\title{
EAP from 1999 to 2020: highlights from chairing the EAPAD conference for 22 years
}

\section{Yoseph Bar-Cohen}

Yoseph Bar-Cohen, "EAP from 1999 to 2020: highlights from chairing the EAPAD conference for 22 years," Proc. SPIE 11375, Electroactive Polymer Actuators and Devices (EAPAD) XXII, 1137502 (22 April 2020); doi: $10.1117 / 12.2559735$

SPIE. Event: SPIE Smart Structures + Nondestructive Evaluation, 2020, Online Only 


\title{
EAP from 1999 to 2020: highlights from chairing the EAPAD conference for 22 years
}

\author{
Yoseph Bar-Cohen \\ Jet Propulsion Laboratory (JPL), California Institute of Technology, \\ 4800 Oak Grove Drive, Pasadena, CA 91109-8099, \\ yosi@jpl.nasa.gov,web: http://ndeaa.jpl.nasa.gov
}

\begin{abstract}
The acronym, EAP (Electroactive polymers), and the synonymous term, artificial muscles, are now well recognized among scientists and engineers worldwide. Prior to 1999, development of such materials has been done at few research institutes in the US, Japan, Italy and Australia and had with minimal visibility and limited cooperation. The EAPAD Conference has been the first major international forum of communicating the development in the field of EAP. At the opening of the first Conf. that was held in 1999, the author posed an arm-wrestling challenge in an effort to promote worldwide advances towards the realization of the potentials of these materials. In posing the challenge, he sought to see EAP activated robotic arms win against human in wrestling match and thus provide a gauge to the technology state. In the contests that were held in 2005 and 2006, the arms lost against the high school female student who wrestled with them - their measured speed and force were about two orders of magnitude lower that the student. Even though no other contest was held since then, the progress in the field indicates that winning the challenge is becoming increasingly more likely. The improvements have led to many applications and many of them were presented at the annual EAPAD conferences and demonstrated at their EAP-in-Action Session. The applications included soft robots, steering mechanisms, brail displays, miniature grippers, loudspeakers, active diaphragm and pumps, toys as well as many others. This manuscript provides a brief review of the advances that were reported since the first EAPAD Conference, including the state of the art, challenges and the expectations for the field.
\end{abstract}

\section{KEYWORDS}

EAP, Electroactive Polymers, Actuators, Biomimetics, Soft Robotics, Artificial Muscles

\section{INTRODUCTION}

For many years, it was well known that some polymers change their shape or size in response to electric, magnetic, chemical, pneumatic, or light stimulation. The convenience and practicality of electric stimulation and the improvements in capability over the last 30 years turned electroactive polymers (EAP) to the most attractive stimulatable polymers [BarCohen and Anderson, 2019; Bar-Cohen, 2004; Bar-Cohen, 2011; https://ndeaa.jpl.nasa.gov/nasa-nde/lommas/eap/WWEAP-Newsletter.html]. The use of EAP materials benefits from the many attractive characteristics of polymers including low mass and cost, as well as fracture tolerance. Further, they can be made with tailorable properties in almost any desirable shape and they are easy to produce and structure using additive manufacturing [Bar-Cohen, 2018]. Prior to the 90s, EAP materials received relatively little attention due to the small number of available materials and their limited actuation capability. The emergence of EAP with large displacement response changed the paradigm of these materials and their potential. The main attractive characteristics of EAP is their operational similarity to biological muscles, particularly their resilience and ability to create large actuation displacement. Taking advantage of these capabilities, unique mechanisms and devices are being explored where EAP serves as actuator to enable new technologies.

Mechanisms actuated by EAPs are enabling engineers to create devices that were previously only imaginable in science fiction [Bar-Cohen and Breazeal, 2003]. Biomimetics technology developers are particularly excited about these materials since they can be used to mimic the movement of animals and insects [Bar-Cohen, 2005; Bar-Cohen, 2011]. In an effort to turn EAP materials to actuators-of-choice, scientist and engineers have been working on the various aspects of the field infrastructure [Bar-Cohen, 2004]. These involve improving the understanding of the basic principles that drive the various EAP materials, as well as developing electro-mechanic analytical tools and effective processing techniques. These resulted in better understanding of the parameters that control their activation force and deformation. Moreover, the processes of synthesizing, fabricating, electroding, shaping and handling have been greatly improved to maximize the EAP materials actuation capability. Further, methods of reliably characterizing the response of these materials have been developed. An essential part of accelerating the transition of EAP to become widely used practical actuators is the ongoing efforts to identify niche applications that address critical needs. For this purpose, efforts are made to exploit the uniqueness of these materials and commercial products are being considered in spite of the limitations of EAP materials. 
For comprehensive documented reference, the author edited a reference book on EAP that has been published in 2001 [Bar-Cohen, 2001] and its $2^{\text {nd }}$ Edition was published in 2004 [Bar-Cohen, 2004]. This book provides a tutorial resource, technology user's guide, and a vision for the future direction of this field. It covers the field various aspects including the available materials, analytical models, processing techniques, and characterization methods. Following the publication of this book, many other books related to EAP were published and the announcement of their publication has been reported in the various issues of the WW-EAP Newsletter [https://ndeaa.jpl.nasa.gov/nasa-nde/lommas/eap/WW-EAPNewsletter.html]

As forums of information exchange, the author initiated in 1999 a website called the WorldWide EAP (WW-EAP) Webhub that archives related information and links to homepages of EAP research and development facilities worldwide [http://eap.jpl.nasa.gov]. In addition, since June 1999 the author has been publishing the semi-annual WW-EAP Newsletter that includes short synopses from authors worldwide providing snapshot of the advances in the field and related biomimetic applications (Figure 1). This Newsletter is published electronically and its archived issues are accessible via the above mentioned WW-EAP webhub [https://ndeaa.jpl.nasa.gov/nasa-nde/lommas/eap/WW-EAP-Newsletter.html]. In December 2019, the $42^{\text {nd }}$ issue of the Newsletter has been published.

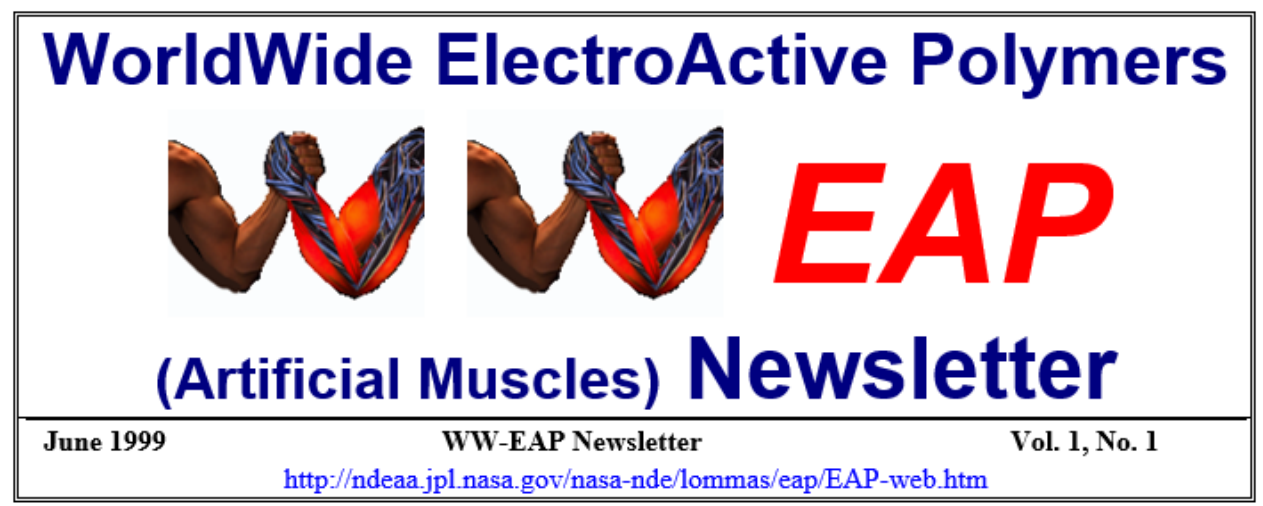

Figure 1: A snapshot from the first issue of the WW-EAP Newsletter.

In effort to promote worldwide advances towards the realization of the potentials of EAP materials, the author posed in 1999, at the opening of the first EAPAD Conf., an armwrestling challenge. In posing this challenge, he sought to see EAP activated robotic arms win against human in wrestling match and thus provide for a simple gauge to the technology state. In the contests that he held in 2005 and 2006, the arms lost against the high school female student who wrestled with them. The student and the EAP actuated arms speed and force were measured and the results showed two orders of magnitude lower capability compared to the student. Even though no other contest was held since then, the progress in the field indicates that winning the challenge is becoming increasingly more likely. The advances are expected to lead to great benefits, particularly in the medical field including effective actuators of prosthetics.

In recognition of the need for international cooperation among the developers, users, and potential sponsors, the author initiated and organized on March 1 and 2, 1999, the first SPIE's EAP Actuators and Devices (EAPAD) Conference. The conference is part of the SPIE's Smart Structures and Materials Symposium [Bar-Cohen, 1999]. The $1^{\text {st }}$ EAPAD was the largest ever on the subject of EAP and it marked an important milestone for the field turning the spotlight onto these emerging materials and their potential. Over the 22 EAPAD conferences, it has continued to be the largest in number of presentations on EAP and attendees. In recent years, there has been increasing number of organizations and technical societies who are organizing workshops, meetings and conferences with sessions on EAP. These include the annual European EAP (EuroAP), which is the international conference on Electromechanically Active Polymer (EAP) transducers $\&$ artificial muscles that is held annually in Europe. This year (i.e., 2020), the EuroAP has reached its $10^{\text {th }}$ anniversary [www.euroeap.eu/conference]. This manuscript provides a brief summary for 22 anniversary of the EAPAD Conference that the author has been chairing since its start and it is the last EAPAD that he is planning to Chair.

\section{THE TYPES OF ELECTROACTIVE POLYMERS (EAP) MATERIALS}

Based on their activation mechanism, EAP materials were divided by the author into two major groups including ionic and electric field activated (that he called electronic) materials (Table 1) [Bar-Cohen and Anderson, 2019; Bar-Cohen, 2004; Bar-Cohen, 2011; Zhang et al, 2004]. The electro-activity of ionic EAP materials involves transport or diffusion of ions. They consist of two electrodes and electrolyte and examples of these materials include conductive polymers, ionic 
polymer gels, ionic polymer-metal composites (IPMC) and carbon nanotubes. Their advantages are the operation under low voltage activation (1-2 Volts) and their generating large bending displacement. Their disadvantages are the need to maintain wetness and their difficulty to sustain constant displacement under DC voltage activation (except for conductive polymers). In contrast to the ionic EAP, the field-activated EAP are driven by Coulomb forces. Examples of these materials are electrostrictive, electrostatic, piezoelectric, and ferroelectric. This type of EAP materials can be made to hold the induced displacement while operated under a DC voltage making them effective for soft robotic applications. These materials have a high mechanical energy density and they can be activated in air with no major constraints. Their disadvantage is the required high activation field $(>20-\mathrm{V} / \mu \mathrm{m})$ that may be close to the electric breakdown level.

TABLE 1: List of the leading EAP materials

\begin{tabular}{|c|c|}
\hline $\begin{array}{l}\text { Ionic EAP } \\
\text { - Carbon Nanotubes (CNT) [Baughman et al., 1999; } \\
\text { Spinks et al., 2004; De Volder et al, 2013] } \\
\text { - Conducting Polymers (CP) [Sansiñena and Olazabal, } \\
\text { 2004; Inzel, 2018] } \\
\text { • ElectroRheological Fluids (ERF) [Bar-Cohen, 2004] } \\
\text { - Ionic Polymer Gels (IPG) [Calvert, 2004; Watanabe et } \\
\text { al, 2014] } \\
\text { - Ionic Polymer Metallic Composite (IPMC) [Oguro et } \\
\text { al., 1999; Nemat-Nasser and Thomas, 2004; Kim, } \\
\text { 2018] }\end{array}$ & $\begin{array}{l}\text { Electric field activatable EAP } \\
\text { - Electrostrictive Graft Elastomers [Su et al., 1999; } \\
\text { Su, 2018] } \\
\text { - Dielectric Elastomer EAP [Pei et al, 2004; Kornbluh } \\
\text { et al., 2004; Madsen et al., 2016] } \\
\text { - Electrostrictive Paper [Kim et al, 2000] } \\
\text { - Ferroelectric Polymers [Zhang, 2018] } \\
\text { - Liquid Crystal Elastomers (LCE) [Guin et al., 2018] }\end{array}$ \\
\hline
\end{tabular}

Table 2: Summary of the advantages and disadvantages of the two major EAP groups.

\begin{tabular}{|c|c|c|}
\hline EAP type & Advantages & Disadvantages \\
\hline Ionic EAP & $\begin{array}{l}\text { - Producing large bending } \\
\text { displacement } \\
\text { - Requiring low activation } \\
\text { voltage } \\
\text { - Naturally exhibiting bi- } \\
\text { directional actuation that } \\
\text { depends on the polarity of the } \\
\text { voltage. }\end{array}$ & $\begin{array}{l}\text { - Except for CPs and CNTs, ionic EAPs do not hold strain } \\
\text { under DC voltage } \\
\text { - Their response is slow (fraction of a second) } \\
\text { - Bending EAPs induce a relatively low actuation force } \\
\text { - Except for CPs, it is difficult to produce these materials with } \\
\text { consistent content } \\
\text { - They involve aqueous system and requires maintaining the } \\
\text { electrolyte content when operating in air. } \\
\text { - They sustain electrolysis at }>1.23 \mathrm{~V} \text { that causes irreversible } \\
\text { process } \\
\text { - They have a low electromechanical coupling efficiency. }\end{array}$ \\
\hline $\begin{array}{l}\text { Field- } \\
\text { activated } \\
\text { EAP }\end{array}$ & $\begin{array}{l}\text { - Can operate in room conditions } \\
\text { for a long time } \\
\text { - Exhibit rapid response at mSec } \\
\text { levels } \\
\text { - Can hold strain under DC } \\
\text { activation } \\
\text { - Induces relatively large } \\
\text { actuation forces }\end{array}$ & $\begin{array}{l}\text { - They require high field strength and this can result in } \\
\text { breakdown. For dielectric elastomers - fields of order of } \\
150 \mathrm{~V} / \mu \mathrm{m} \text { may be needed and } \sim 10 \% \text { strain can be induced. } \\
\text { Using composite DE allows for lower activation voltage } \\
(\sim 20 \mathrm{~V} / \mu \mathrm{m}) \text { [Bar-Cohen } 2004 \text {; Cheng and Zhang, 2008]. } \\
\text { - The electrostriction dictates mono-polar actuation that is } \\
\text { independent of the voltage polarity. }\end{array}$ \\
\hline
\end{tabular}

The induced displacement of both EAP material types can be designed geometrically to bend, stretch or contract. Any of the existing EAP materials can be made to bend with a significant response offering an actuator with an easy to see reaction. To induce bending in the case of linear strain actuation, the EAP material is bonded to a passive film and it acts as a bimorph. Generally, the bending that is produced by EAP materials involves low force due to the low modulus and, therefore, provides low moment and torque.

EAP materials are still custom made mostly by researchers and they are not available in commercial quantities. To help in making these materials widely available, the author established a website that provides fabrication procedures for the leading types of EAP materials as well as website about sources for purchasing custom made materials and samples [see links on http://eap.jpl.nasa.gov]. 


\section{THE ARMWRESTLING CHALLENGE AS A MEASURE OF THE TECHNOLOGY STATE}

The capability of EAP materials as artificial muscles has been quite improved as the result of the many years of investments and the large number studies and development by scientists and engineers who have been working on these materials and their applications. As mentioned earlier, in 1999, in an effort to promote worldwide development that will realize the potential of EAP materials - the author posed the armwrestling challenge [http://ndeaa.jpl.nasa.gov/nasande/lommas/eap/EAP-armwrestling.htm]. A graphic rendering of this challenge is illustrated in Figure 2, which became its icon. The emphasis on armwrestling with human was chosen since these materials are viewed as artificial muscles and, therefore, biological muscles serve as a baseline for the performance comparison. In posing this challenge, the author is seeking to see an EAP activated robotic arm win against human in a wrestling match to provide engineers and the public worldwide a gauge for the state of the technology. Success in wrestling against humans will indicate that EAP materials are ready to be applied at the level of the human muscles performance. This will allow improving many aspects of our life including the actuation of lightweight prosthetics; realistic biologically inspired robots as well as many other biomimetic mechanisms with unmatched capability.

The first contest of an armwrestling match between EAP-actuated arms and human was held against a 17-year old high school female student, on March 7, 2005, as part of the EAP-in-Action Session of the SPIE's EAPAD Conference. Three EAP actuated robotic arms participated in the contest and the girl won against all these arms. The participating organizations that made these arms were Environmental Robots Incorporated (ERI), Albuquerque, NM; Swiss Federal Laboratories for Materials Testing and Research, EMPA, Dubendorf, Switzerland; and Senior Students from the Engineering Science and Mechanics Dept., Virginia Tech.

The second armwrestling Contest was held on Feb. 27, 2006 and had three participants including ERI Limited, Albuquerque, NM; and two groups of students from Virginia Tech. Rather than directly wrestling with a human opponent, the contest consisted of measuring the performance of the female student and the EAP actuated arms and comparing their results. The measuring fixture (Figure 3) was developed jointly by individuals from UCLA and the author's group at JPL. The fixture was strapped to a table and the EAP actuated arms were tested for speed and pulling force. Each competing arm pulled on the fixture cable that has a force gauge on its other end. To simulate a wrestling action, a $0.5-\mathrm{kg}$ weight was mounted on the pulling cable and the competing arms had to lift this weight to the top of the fixture. The time to reach the fixture's top over the fixed distance was measured to determine the wrestling speed. Once the weight reaches the top, the cable is stretched and it pulls on the gauge allowing measurement of the pulling force. To establish a baseline for performance comparison, the capability of the female student, who was the same human wrestler in 2005, was measured first and then the three participating robotic arms were tested. The strongest arm was the one made by senior students from the Dept. of Engineering Science and Mechanics, Virginia Tech, and it was an enhancement of the arm that they used in the 2005 contest.

In a future conference, once advances in developing such arms reach sufficiently high level, a professional wrestler will be invited for the next human/machine wrestling match.

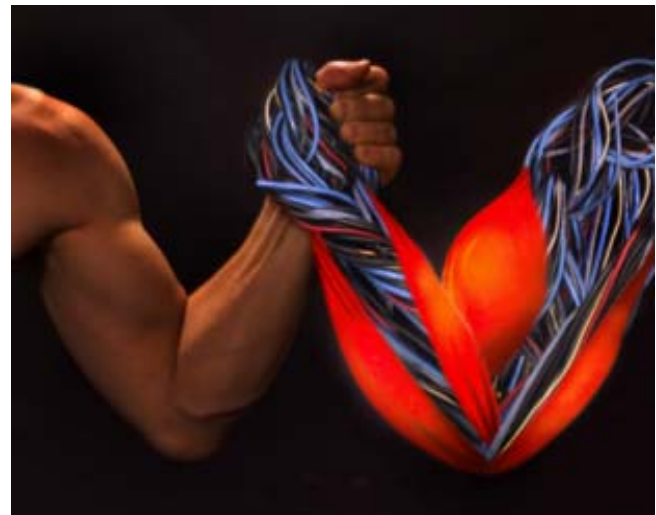

Figure 2: The grand challenge for the EAP actuated robotic arms.

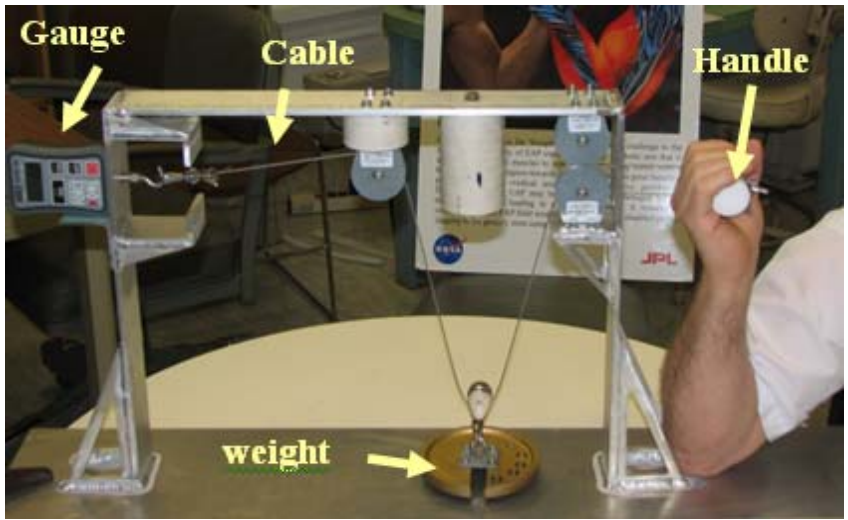

Figure 3: The fixture for testing the pulling force and speed of the human wrestler and the EAP actuated robotic arms.

\section{SUMMARY}

Nature offers proven mechanisms as a model for inspiration and mimicking that can be used to significantly improve our lives and enormously enhance the capability of the tools we use. Artificial muscles, i.e. EAP materials, are one of the technologies that are enabling new bioinspired mechanisms. These materials are quite attractive due to the simplicity of electric excitation and control as well as the large deformation that they produce. As polymers, EAP materials offer many 
attractive characteristics that include low weight, fracture tolerant, as well as the easy additive manufacturability. Further, they can be configured into almost any conceivable shape and their properties can be tailored to suit a broad range of requirements. These capabilities and the significant ability to change their shape or size under electrical stimulation are inspiring numerous possibilities in many different disciplines.

Turning EAP materials, which have mostly emerged in the 90s, into actuators-of-choice required a well-established infrastructure. This involved improving a full range of science and engineering topics from basic science to fabrication and applications. Many studies have taken place and reported in various forums including the proceedings of the annual EAPAD Conference. The processes of synthesizing, fabricating, electroding, shaping and handling are being refined to maximize the EAP materials actuation capability. Methods of reliably characterizing the response of these materials were developed and efforts are being made to establish database with documented material properties in order to support design engineers that are considering the use of these materials.

The application of these materials as actuators to drive manipulation, mobility and robotic devices involves multidisciplines including material science, electro-mechanics, computers and electronics. Even though the actuation force of the known EAP materials and their robustness require further improvement, there has already been many reported successes. Using EAP to replace existing actuators may be a difficult challenge and therefore it is highly desirable to identify niche applications where EAP materials would not need to compete with existing technologies.

The EAPAD Conference, which was initiated and chaired by the author over the last 22 years, is expected to continue to be the leading forum for reporting the progress and break-through in their capability and applications.

\section{ACKNOWLEDGEMENT}

Some of the research reported in this manuscript was conducted at the Jet Propulsion Laboratory (JPL), California Institute of Technology, under a contract with the National Aeronautics and Space Administration (NASA).

\section{REFERENCE}

Bar-Cohen Y., (Ed.), (1999), Proceedings of the first SPIE's Electroactive Polymer Actuators and Devices (EAPAD) Conf., Smart Structures and Materials Symposium, Volume 3669, SPIE Press, Bellingham, Washington, ISBN 08194-3143-5, pp. 1-414.

Bar-Cohen Y., (Ed.), (2001), "Electroactive Polymer (EAP) Actuators as Artificial Muscles - Reality, Potential and Challenges," ISBN 0-8194-4054-X, SPIE Press, Vol. PM98, pp. 1-671

Bar-Cohen Y., (2004), "Electroactive Polymer (EAP) Actuators as Artificial Muscles - Reality, Potential and Challenges," 2nd Edition, ISBN 0-8194-5297-1, SPIE Press, Bellingham, Washington, Vol. PM136, pp. 1-765

Bar-Cohen Y., and C. Breazeal (Eds.), (2003), "Biologically-Inspired Intelligent Robots," SPIE Press, Bellingham, Washington, Vol. PM122, ISBN 0-8194-4872-9 pp. 1-393

Bar-Cohen Y., (Ed.), (2005), "Biomimetics - Biologically Inspired Technologies," CRC Press, Boca Raton, Florida, ISBN 0849331633 , pp. $1-527$

Bar-Cohen Y., (Ed.), (2011), Biomimetics: Nature-Based Innovation, ISBN: 9781439834763, ISBN 10: 1439834768, CRC Press, Taylor \& Francis Group, Boca Raton, Florida, pp. 1-788. https://www.crcpress.com/Biomimetics-NatureBased-Innovation/Bar-Cohen/p/book/9781439834763

Bar-Cohen Y. and I. Anderson, (22 March 2019), "Electroactive Polymer (EAP) Actuators - Background Review", Review Paper, Invited review paper, Journal on Mechanics of Soft Materials (MOSM), Springer Nature Switzerland AG 2019, Springer International Publishing, 1: 5. https://doi.org/10.1007/s42558-019-0005-1, Springer International Publishing 14 pages https://rdcu.be/bstXj

Baughman R.H., C. Cui, A. A. Zakhidov, Z. Iqbal, J. N. Basrisci, G. M. Spinks, G. G. Wallace, A. Mazzoldi, D. de Rossi, (1999) A. G. Rinzler, O. Jaschinski, S. Roth and M. Kertesz, "Carbon Nanotune Actuators," Science, Vol. 284, pp. 1340-1344.

Calvert P., (2004), "Electroactive Polymer Gels," Chapter 5, in [Bar-Cohen, 2004), pp. 95-148.

Cheng Z., and Q. Zhang, (2008), "Field-Activated Electroactive Polymers," Special Issue dedicated to EAP, Materials Research Society (MRS) Bulletin, Vol. 33, No. 3, pp. 190-195.

De Volder M. F. L., S. H. Tawfick, R. H. Baughman, and A. J. Hart, (01 Feb 2013), “Carbon Nanotubes: Present and Future Commercial Applications", Science, Vol. 339, Issue 6119, pp. 535-539 DOI: 10.1126/science.1222453

Guin T., M. J. Settle, B. A. Kowalski, A. D. Auguste, R. V. Beblo, G. W. Reich and T. J. White (2018), "Layered liquid crystal elastomer actuators", Nature Communications, volume 9, Article number: 2531, Open Access Journal, https://www.nature.com/articles/s41467-018-04911-4

Inzelt G., (2018), “Conducting polymers: past, present, future”, J. Electrochem. Sci. Eng. 8(1) 3-37; DOI:

http://dx.doi.org/10.5599/jese.448 Open Access 
Kim J., J.-Y. Kim and S.-J. Choe, (2000) "Electro-Active Papers: Its Possibility as Actuators," Y. Bar-Cohen Y., (Ed.), Proceedings of the SPIE's EAPAD Conf., part of the $7^{\text {th }}$ Annual International Symposium on Smart Structures and Materials, Vol. 3987, SPIE Press, Bellingham, Washington, ISBN 0-8194-3605-4, pp 203-209.

Kim K. J., (2018), "Last twenty-five years of effort in developing fabrication-methods of IPMCs", Paper No. 10594-9, and I Anderson (Eds.), Proceedings of the EAPAD Conference, SPIE Smart Structures and Materials Symp., Held in Denver, CO.

Kornbluh R., R. Pelrine, Q. Pei, and V. Shastri, (2004), “Application of Dielectric EAP Actuators," Chapter 16 in [BarCohen, 2004], pp. 529-581.

Madden J. D.W., P. G.A. Madden, and I. W. Hunter, (2001), "Characterization of polypyrrole actuators: modeling and performance", Proceedings of SPIE $8^{\text {th }}$ Annual Symposium on Smart Structures and Materials: Electroactive Polymer Actuators and Devices, Y. Bar-Cohen, Ed., SPIE Press, Bellingham, Washington, 72-83.

Madsen, F.B., A. E. Daugaard, S. Hvilsted, and A. L. Skov, (2016), "The Current State of Silicone-Based Dielectric Elastomer Transducers," Macromolecular Rapid Communications 37 (5), pp. 378-413.

Nemat-Nasser S., and C. W. Thomas, (2004), "Ionomeric Polymer-Metal Composites," Ch. 6, in [Bar-Cohen, Y., 2004], pp. 171-230.

Oguro K., N. Fujiwara, K. Asaka, K. Onishi, and S. Sewa, (1999), "Polymer electrolyte actuator with gold electrodes," Proceedings of the SPIE's 6th Annual International Symposium on Smart Structures and Materials, SPIE Press, Bellingham, Washington, Proc. Vol. 3669, pp. 64-71.

Pei Q., R. Pelrine, M. Rosenthal, S. Stanford, H. Prahlad, R. Kornbluh, (2004), "Recent progress on electroelastomer artificial muscles and their application for biomimetic robots," Proc. SPIE EAPAD Conf., Y. Bar-Cohen, (Ed.), SPIE Press, Bellingham, Washington, Vol. 5385, pp. 41-50.

Sansiñena J. M., and V. Olazabal, (2004), “Condictive Polymers,” Ch. 7, in [Bar-Cohen, Y., 2004], pp. 231-259.

Spinks, G. M., G. G. Wallace, R. H. Baughman, and L. Dai, (2004), "Carbon Nanotube Actuators: Synthesis, Properties and Performance," Ch. 8, in [Bar-Cohen, 2004], pp. 261-295.

Su J., J. S. Harrison, T. St. Clair, Y. Bar-Cohen, and S. Leary, (1999), "Electrostrictive graft elastomers and applications," MRS Symp. Proceedings, Vol. 600, Warrendale, PA, pp. 131-136.

Su J., (2018), “A review of electrostrictive graft elastomers: structures, properties, and applications”, Paper No. 10594-23, Y. Bar-Cohen and I Anderson (Eds.), Proceedings of the EAPAD Conference, SPIE Smart Structures and Materials Symp., Held in Denver, CO.

Watanabe M., S. Imaizumi, T. Yasuda, and H. Kokubo, (2014), “Ion Gels for Ionic Polymer Actuators”, K. Asaka (Ed.), Soft Actuators Soft Actuators - Materials, Modeling, Applications, and Future Perspectives, Springer Link, https://link.springer.com/book/10.1007/978-4-431-54767-9 pp 141-156 DOI: https://doi.org/10.1007/978-4-431$\underline{54767-9}$

Zhang Q., C. Huang, and F. Xia, (2004), "Electric field activated EAP,” Chapter 4 in [Bar-Cohen, 2004], pp. 95-148.

Zhang Q., (2018), "Molecular machine: how ferroelectric polymers generate giant electrostriction" paper 10594-3, Y. BarCohen and I Anderson (Eds.), Proceedings of the EAPAD Conference, SPIE Smart Structures and Materials Symp., Held in Denver, CO.

\section{INTERNET REFERENCES}

- Armwrestling Challenge: http://ndeaa.jpl.nasa.gov/nasa-nde/lommas/eap/EAP-armwrestling.htm

- Books and proceedings: http://ndeaa.jpl.nasa.gov/nasa-nde/yosi/yosi-books.htm

- EAP Conferences: http://ndeaa.jpl.nasa.gov/nasa-nde/lommas/eap/eap-conferences.htm

- EAP Fabrication procedures http://ndeaa.jpl.nasa.gov/nasa-nde/lommas/eap/EAP-recipe.htm

- Sources of obtaining EAP materials http://ndeaa.jpl.nasa.gov/nasa-nde/lommas/eap/EAP-material-nproducts.htm

- WW-EAP Newsletter: http://ndeaa.jpl.nasa.gov/nasa-nde/lommas/eap/WW-EAP-Newsletter.html

- WW-EAP Webhub: http://eap.jpl.nasa.gov 